\title{
Emergency department 72-hour revisits among children with chronic diseases: a Saudi Arabian study
}

\author{
Anwar E. Ahmed ${ }^{1,2,5^{*}}$, Bashayr I. ALMuqbil ${ }^{2}$, Manair N. Alrajhi ${ }^{2}$, Hend R. Almazroa $^{2}$, Doaa A. AlBuraikan², \\ Monirah A. Albaijan', Maliha Nasim', Majid A. Alsalamah², Donna K. McClish³ and Hamdan AL-Jahdalii ${ }^{2,4,5^{*}}$
}

\begin{abstract}
Background: Emergency Department (ED) revisits have often been used as an indicator of medical care quality. This study aimed to quantify the frequency of ED revisits within $72 \mathrm{~h}$ of discharge and identify its factors among children with chronic diseases.

Methods: We designed a retrospective cohort study of children with at least one chronic disease who were also under 18 years of age and had attended and were discharged from the ED at King Abdullah Specialist Children's Hospital (KASCH-RD), Riyadh, Saudi Arabia between April 19, 2015 and July 29, 2017. The outcome measure was the frequency of ED revisits during a period of $72 \mathrm{~h}$ after discharge.

Results: The study included 11,057 ED discharges of children with at least one chronic disease. Their revisit rate was 1211 (11\%), with 83 (6.9\%) having had a second ED revisit within 72 h of ED discharge. According to ICD-10 codes, the most common causes of ED revisits were respiratory, digestive, genitourinary, symptoms, and external causes. Factors of frequent ED revisits within $72 \mathrm{~h}$ were young age, institutional health insurance coverage, year of new health information system (2015), external causes, and genitourinary.

Conclusion: The rate of 72-h ED revisits after discharge of children with chronic diseases treated at KASCH-RD was relatively high, and was associated with young age, institutional health insurance coverage, year of a new health information system implementation, and external causes of ED visit. These study findings amplify the need for intervention to reduce the rate of early ED revisits among children with chronic diseases.
\end{abstract}

Keywords: Emergency department, ED revisit, Chronic diseases, Children, Saudi Arabia

\section{Background}

Overcrowding in pediatric emergency departments (EDs) places a heavy burden on healthcare systems in terms of financial costs $[1,2]$ and potential infection-related ED visits [3]. Recently, significant interest and research has focused on the number of return-to-emergency department (ED) visits, as it represents a quality benchmark for patient safety and care [4-6]. This number also contributes to overcrowding in EDs, as some visits are unnecessary $[4,7]$.

\footnotetext{
*Correspondence: ahmeda5@vcu.edu; jahdalih@gmail.com

${ }^{1}$ King Abdullah International Medical Research Center (KAIMRC), Riyadh, Saudi Arabia

${ }^{2}$ King Saud bin Abdulaziz University for Health Sciences, National Guard Health Affairs, P.O. Box 22490, Riyadh 11426, Saudi Arabia

Full list of author information is available at the end of the article
}

ED visits were observed in patients of various age groups, with a large amount having been noticed in children [8]. Earlier studies have assessed the rate of ED revisits among children in general: it ranges between 2.7 and 19\% [9-17]. However, a high frequency of ED revisits was observed in children with chronic diseases $[14,15]$. The large variation rates of ED revisits among children highlights the need for more evaluation, particularly in unstudied populations.

In several international reports, the greater rate of ED revisits in children has been attributed to young age $[9,12,15,18]$ and health insurance coverage [18-20]. Recent Saudi Arabian studies, however, have documented that chronic diseases are the top cause of death among

(c) The Author(s). 2018 Open Access This article is distributed under the terms of the Creative Commons Attribution 4.0 International License (http://creativecommons.org/licenses/by/4.0/), which permits unrestricted use, distribution, and reproduction in any medium, provided you give appropriate credit to the original author(s) and the source, provide a link to the Creative Commons license, and indicate if changes were made. The Creative Commons Public Domain Dedication waiver (http://creativecommons.org/publicdomain/zero/1.0/) applies to the data made available in this article, unless otherwise stated. 
children in Saudi Arabia [21, 22], and have become a major priority in Saudi Vision 2030.

Despite the fact that revisits to the ED are well recognized as a key for quality improvement [4-6], no data exists in Saudi Arabia regarding the rate of ED revisits among children with chronic diseases. This study attempts to investigate the frequency of ED revisits at a major Saudi hospital and the common causes, and to identify factors among children with chronic diseases associated with the high rate of 72-h ED revisits after discharge. We assessed the hypothesis that younger children, health insurance coverage, year of a new health information system implementation, and causes of ED visits may be associated with the high rate of ED revisits within $72 \mathrm{~h}$ among the study population.

\section{Methods}

This is a retrospective study of all ED discharges of children with chronic diseases under the age of 18 years who attended the ED at King Abdullah Specialist Children's Hospital, Riyadh (KASCH-RD) between April 19, 2015 and July 29, 2017. The study obtained approval from the Institutional Review Board (IRB) at the Ministry of National Guard - Health Affairs (MNG-HA), approval \#RC17/081/R.

The ED records of eligible children were retrieved from the institution's BESTCare database. In 2015, the children's hospital implemented a new integrated health information system, BESTCare. It is a unified database that allows integration of all main hospital units: inpatient, outpatient, emergency, intensive care, and operating room. All medical documentation, medical orders, medication histories, and radiology and lab results are stored in chronological order [23]. Housing a wide range of administration and clinical activity (including a clinical data warehouse), it also benefits from a clinical decision support system that highlights standardized clinical guidelines of procedures to be followed for certain conditions, and issues alerts to physicians, on ordering investigations or prescribing medication that may be contraindicated or unsafe [23]. We defined the study population as children with at least one chronic disease who were discharged from the ED at KASCH-RD during the study period. We included the main types of chronic diseases that require long-term control [24]. These chronic diseases were defined by the Saudi Ministry of Health as national health priorities for prevention and treatment, such as cardiovascular disease, diabetes mellitus, hypertension, cancer, pulmonary disease, and asthma [25].

The study data included age, gender, institutional health insurance status (yes/no), new patient or patient has not received healthcare services in our facility (yes/ no), year of ED visit (2015, 2016, or 2017). Patients' ages were classified into 4 groups: $<3$ years, $3 \leq$ age $<6$ years, $6 \leq$ age $<14$ years, and $\leq 14$ age $<18$ years old.

In our center the health coverage includes 3 categories: 1) Ministry of National Guard employees and their dependents who are fully covered. 2) those with private health insurance coverage and 3) those without insurance but covered exceptionally based on their case complexity. We reclassified health insurance status into two groups; institutionally insured or privately insured. In our center the emergency department is open to all emergency cases. Case that sever or need urgent admission will be admitted to our hospital regardless of their insurance coverage, or nationalities.

The study units of analysis are ED discharges of children with at least one chronic disease. The study outcome was the number of ED revisits within $72 \mathrm{~h}$ of discharge $(0,1,2$ etc). The causes of initial ED visit/revisits were classified according to the International Statistical Classification of Diseases and Related Health Problems (10th version, Australian modification) code, chapters I "Certain infectious and parasitic diseases" to XXII "Codes for special purposes" [26]. The ICD-10 is publically available at http://apps.who.int/classifications/ icd10/browse/2016/en\#/XVIII.

\section{Data analysis}

The data analysis was performed using IBM SPSS v. 25 (IBM Corp., Armonk, NY, USA). Subject characteristics were illustrated as frequency and percentage (Table 1). The most common causes reported at the first ED revisit and the second ED revisit within $72 \mathrm{~h}$ were presented in bar charts (Figs. 1 \& 2). The bar charts were generated using Microsoft Excel 2010. A univariate Poisson regression model was used to calculate the unadjusted relative rate ( $\mathrm{URR}$ ) and assess differences in the rate of ED revisits within $72 \mathrm{~h}$ of ED discharge across children's characteristics. Multiple Poisson regression models were used to calculate the adjusted relative rate (aRR) and identify independent factors that were associated with the high rate of ED revisits within $72 \mathrm{~h}$ of ED discharge. Table 2 shows the findings of Poisson regression models: $p$-value (P), RR, and confidence intervals (CI) for RR. A $P \leq 0.05$ was considered significant.

\section{Results}

The KASCH-RD ED medical records of 11,057 ED discharges for children with chronic diseases were analyzed. Of the ED discharges, 1211/11,057 (11\%) had a first ED revisit, and 83/1211 (6.9\%) had a second ED revisit within $72 \mathrm{~h}$. The median age was 4.9 ( 25 percentile $=2.3$ and 75 percentile $=8.7$ years), with $60.1 \%$ being males. Among the ED discharges, 618 (5.6\%) children were admitted to the hospital. Table 1 summarizes the sample 
Table 1 Characteristics of ED discharges at KASCH-RD between September 13, 2015 and July 29, 2017

\begin{tabular}{|c|c|c|c|}
\hline Characteristics & Levels & Number & Percentage \\
\hline \multirow[t]{4}{*}{ Age } & $<3$ years & 2735 & 32.1 \\
\hline & $3 \leq$ Age $<6$ years & 2192 & 25.8 \\
\hline & $6 \leq$ Age $<14$ years & 3151 & 37.0 \\
\hline & $\geq 14$ years & 432 & 5.1 \\
\hline \multirow[t]{2}{*}{ Gender } & Female & 3394 & 39.9 \\
\hline & Male & 5116 & 60.1 \\
\hline \multirow[t]{2}{*}{ Institutional health insurance coverage } & Yes & 8223 & 96.6 \\
\hline & No & 287 & 3.4 \\
\hline \multirow[t]{3}{*}{ Year of ED visit } & 2015 & 2538 & 23.0 \\
\hline & 2016 & 5663 & 51.2 \\
\hline & 2017 & 2856 & 25.8 \\
\hline \multirow[t]{2}{*}{ New patient ED visit } & Yes & 533 & 17.4 \\
\hline & No & 2526 & 82.6 \\
\hline \multirow[t]{8}{*}{ Causes of initial ED visit } & Circulatory & 362 & 3.3 \\
\hline & Congenital malformations & 371 & 3.4 \\
\hline & Digestive & 2046 & 18.5 \\
\hline & Ear & 478 & 4.3 \\
\hline & External causes & 851 & 7.7 \\
\hline & Genitourinary & 1954 & 17.7 \\
\hline & Respiratory & 2606 & 23.6 \\
\hline & Other & 2389 & 21.6 \\
\hline \multicolumn{4}{|l|}{ Initial ED discharges $(N=11,057)$} \\
\hline \multirow[t]{2}{*}{ Had first revisit within $72 \mathrm{~h}$} & No & 9846 & 89.0 \\
\hline & Yes & 1211 & 11.0 \\
\hline \multirow[t]{2}{*}{ Had a second revisit within $72 \mathrm{~h}$} & No & 1128 & 93.1 \\
\hline & Yes & 83 & 6.9 \\
\hline
\end{tabular}

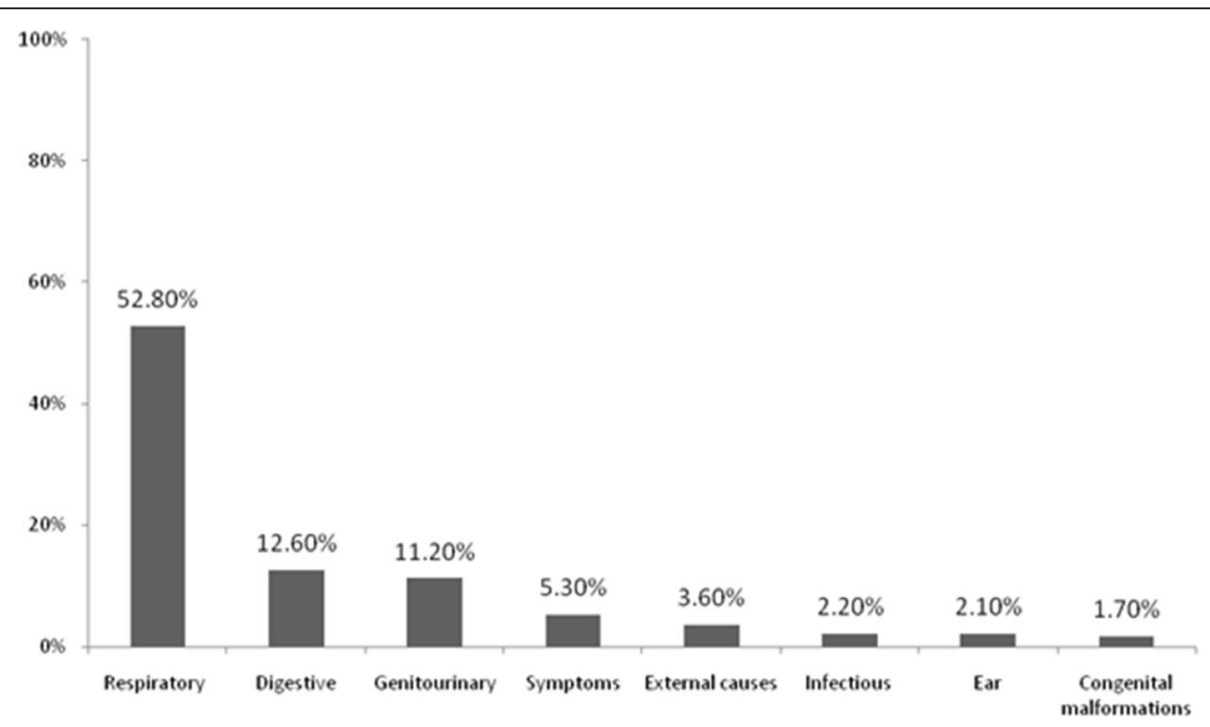

Fig. 1 The most common causes at the first ED revisit within $72 \mathrm{~h}$ of discharge 


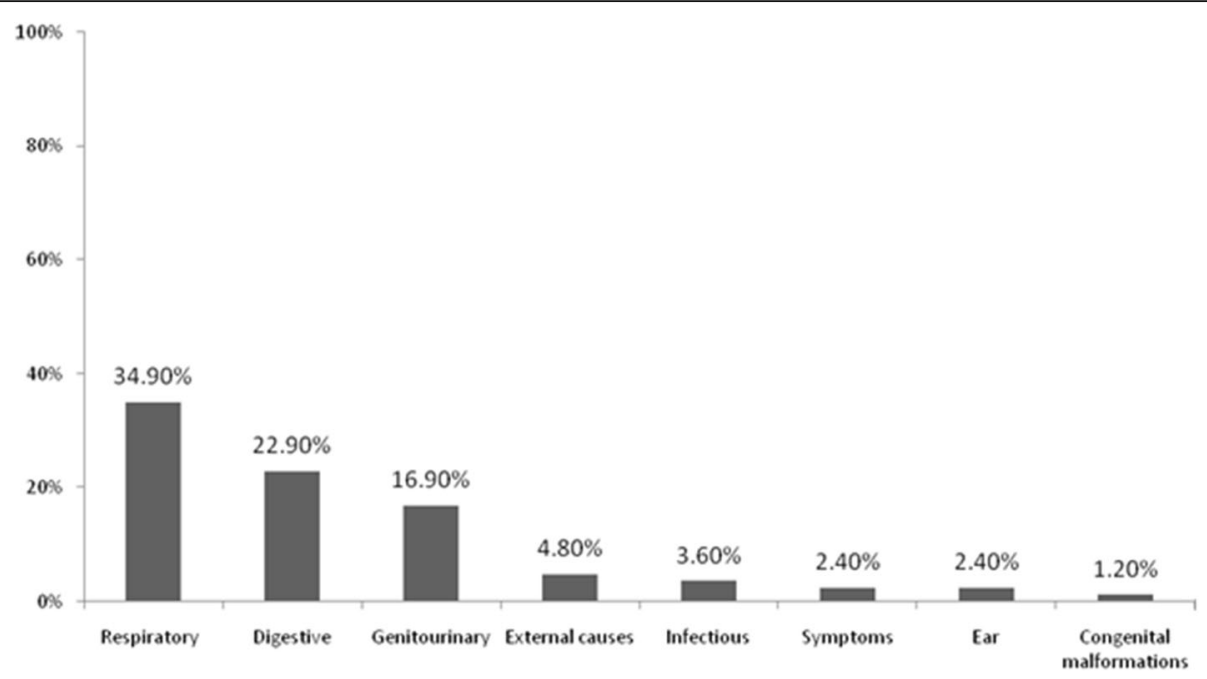

Fig. 2 The most common causes at the second ED revisit within $72 \mathrm{~h}$ of discharge

characteristics. Among children studied, the 6 most common chronic diseases were asthma (8.9\%), allergy (3.6\%), heart disease (1.6\%), eczema (1\%), anemia (0.6\%), and diabetes $(0.2 \%)$.

The most common causes at the initial ED visit were respiratory (23.6\%), digestive (18.5\%), genitourinary (17.7\%), and external causes of morbidity and mortality (7.7\%). The most common causes on the first ED revisit were respiratory (52.8\%), digestive (12.6\%), genitourinary (11.2\%), symptoms, signs, and abnormal clinical and laboratory findings (5.3\%), and external causes of morbidity and mortality (3.6\%) (Fig. 1). The most common causes on the second ED revisit were respiratory (34.9\%), digestive (22.9\%), genitourinary (16.9\%), external causes of morbidity and mortality (4.8\%), along with symptoms, signs, and abnormal clinical and laboratory findings (2.4\%) (Fig. 2).

The results of unadjusted and adjusted Poisson analyses of the number of revisits within $72 \mathrm{~h}$ after ED discharge are illustrated in Table 2. The unadjusted relative risk (uRR) significantly increased in children with chronic diseases of age $<3$ years $(\mathrm{uRR}=3.293, P=$ $0.001), 3 \leq$ age $<6$ years ( $\mathrm{uRR}=3.114, P=0.001)$, and $6 \leq$

Table 2 Factors associated with higher rate of ED revisits within $72 \mathrm{~h}$ of discharge

\begin{tabular}{|c|c|c|c|c|c|c|c|c|c|}
\hline \multirow[b]{3}{*}{ Factor } & \multirow[b]{3}{*}{ Reference } & \multicolumn{4}{|c|}{ Univariate } & \multicolumn{4}{|c|}{ Multivariate } \\
\hline & & \multirow[b]{2}{*}{$P$} & \multirow[b]{2}{*}{$\mathrm{RR}$} & \multicolumn{2}{|c|}{ 95\% Wald CI for RR } & \multirow[b]{2}{*}{ P } & \multirow[b]{2}{*}{$\mathrm{aRR}$} & \multicolumn{2}{|c|}{ 95\% Wald Cl for aRR } \\
\hline & & & & Lower & Upper & & & Lower & Upper \\
\hline Age $<3$ years & $\geq 14$ years & $0.001^{*}$ & 3.293 & 2.103 & 5.158 & $0.001^{*}$ & 6.056 & 2.461 & 14.904 \\
\hline $3 \leq$ Age $<6$ years & $\geq 14$ years & $0.001^{*}$ & 3.114 & 1.982 & 4.893 & $0.001^{*}$ & 4.831 & 1.930 & 12.091 \\
\hline $6 \leq$ Age $<14$ years & $\geq 14$ years & $0.001^{*}$ & 2.392 & 1.524 & 3.754 & $0.036^{*}$ & 2.663 & 1.068 & 6.641 \\
\hline Female & Male & 0.830 & 1.013 & 0.898 & 1.143 & 0.094 & 1.253 & 0.962 & 1.633 \\
\hline Institutional health insurance coverage & None & $0.001^{*}$ & 4.239 & 2.200 & 8.168 & $0.025^{*}$ & 3.132 & 1.152 & 8.518 \\
\hline Year 2015 & Year 2017 & $0.001^{*}$ & 1.363 & 1.166 & 1.593 & $0.001^{*}$ & 2.040 & 1.390 & 2.993 \\
\hline Year 2016 & Year 2017 & $0.001^{*}$ & 1.288 & 1.124 & 1.475 & $0.050^{*}$ & 1.427 & 1.000 & 2.037 \\
\hline New patient ED visit & No & 0.341 & 0.833 & 0.572 & 1.213 & 0.950 & 0.988 & 0.681 & 1.434 \\
\hline Circulatory & Other & 0.687 & 1.075 & 0.756 & 1.529 & 0.595 & 0.858 & 0.487 & 1.511 \\
\hline Congenital malformations & Other & 0.296 & 1.195 & 0.856 & 1.667 & 0.102 & 1.401 & 0.935 & 2.099 \\
\hline Digestive & Other & $0.001^{*}$ & 1.490 & 1.249 & 1.777 & 0.141 & 1.456 & 0.883 & 2.399 \\
\hline Ear & Other & $0.026^{*}$ & 1.380 & 1.039 & 1.832 & 0.518 & 1.217 & 0.671 & 2.204 \\
\hline External causes & Other & 0.449 & 0.902 & 0.690 & 1.178 & $0.039^{*}$ & 1.944 & 1.034 & 3.657 \\
\hline Genitourinary & Other & $0.001^{*}$ & 1.765 & 1.487 & 2.095 & $0.002^{*}$ & 1.814 & 1.251 & 2.631 \\
\hline Respiratory & Other & $0.001^{*}$ & 1.435 & 1.212 & 1.699 & $0.001^{*}$ & 0.111 & 0.035 & 0.351 \\
\hline
\end{tabular}

*. Significant at $a=0.05$ 
age $<14$ years $(\mathrm{uRR}=2.392, P=0.001)$ compared to children with chronic diseases of age $\geq 14$ years. Among children with chronic diseases, institutional health insurance coverage was associated with a higher frequency of revisits within $72 \mathrm{~h}(\mathrm{uRR}=4.239, \mathrm{P}=0.001)$. The risk of revisits within $72 \mathrm{~h}$ was higher for children with chronic diseases who visited the ED in 2015 (uRR $=1.363, P=$ 0.001 ) and 2016 (uRR $=1.288, P=0.001$ ) compared to children who visited the ED in 2017. Causes for ED visits, such as digestive diseases ( $\mathrm{uRR}=1.490, P=0.001$ ), genitourinary diseases ( $\mathrm{uRR}=1.765, P=0.001)$, respiratory diseases $(\mathrm{uRR}=1.435, P=0.001)$, and ear diseases (uRR $=1.380, P=0.026$ ) were also significant predictors for a higher frequency of revisits within $72 \mathrm{~h}$.

Independent risk factors for ED revisits within $72 \mathrm{~h}$ included age, year, institutional health insurance coverage, external causes, and genitourinary diseases (Table 2). Children with chronic diseases of a younger age were associated with a higher risk of ED revisits within $72 \mathrm{~h}$ : age $<3$ years $(\mathrm{aRR}=6.056, P=0.001), 3 \leq$ age $<6$ years $(\mathrm{aRR}=4.831, P=0.001)$, and $6 \leq$ age $<14$ years $(\mathrm{aRR}=$ 2.663, $P=0.036$ ) compared to children of age $\geq 14$ years. The rate of ED revisits within $72 \mathrm{~h}$ was higher for children with institutional health insurance than for children without health insurance $(\mathrm{aRR}=3.132, P=0.025)$. The year of implementing a new health information system (2015) significantly predicted a high rate of ED revisits within $72 \mathrm{~h}(\mathrm{aRR}=2.040, P=0.001)$, and the following year $2016(\mathrm{aRR}=1.427, P=0.050)$, compared to 2017 . Among children with chronic diseases, external causes of morbidity and mortality $(\mathrm{aRR}=1.944, P=0.039)$ and genitourinary $(\mathrm{aRR}=1.814, P=0.002)$ were associated with a higher rate of revisits within $72 \mathrm{~h}$ after ED discharge. Gender was not associated with 72-h ED revisits among children with chronic diseases.

\section{Discussion}

In this retrospective study, we included all ED discharges of patients with chronic diseases under the age of 18 years who were admitted to the ED at KASCH-RD between April 19, 2015 and July 29, 2017. This represents the first Saudi Arabian evaluation of children with chronic diseases re-attending the ED within $72 \mathrm{~h}$ after ED discharge. Our main aim was to determine the frequency of ED revisits and the main causes, as well as to identify characteristics associated with the high rate of 72-h ED revisits among children with chronic diseases.

A rather high ED revisit rate (11\%) was observed among children with chronic diseases in Saudi Arabia as compared to the general global children's population: USA $2.7 \%$ [9], Singapore 4.3\% [10], Canada 4.4\% [11], and Taiwan $6.47 \%$ [12]. It may not be possible to compare this study's findings with these studies, as in our study we calculated the rate of ED revisit in a definitive group, specifically children with chronic diseases. However, this comparison indicates that the presence of chronic diseases is associated with a high rate of ED utilization.

A similar ED revisit rate was found in earlier investigations: two studies among young children with gastroenteritis [13] and common illnesses [15] showed 16\%. In our study, we evaluated revisits within 72-h of ED discharge, and it should be noted that these two studies have evaluated longer time spans of ED revisits. For instance, Freedman et al. [13] evaluated revisits within 7 days.

Reducing early ED revisits at KASCH-RD must be a hospital priority to reduce unnecessary costs [16] and improve quality of services [17]. Understanding the reasons for ED revisits among children with chronic diseases, based on the initial ED visit discharge, may allow implementing intervention or guidelines to reduce the ED revisit rates. To reduce avoidable ED revisits, this could involve applying a predetermined framework on early follow-up and parent education on home management.

In the KASCH-RD center, respiratory conditions were found to be the most frequent cause of initial ED visits. This is in agreement with Goh et al., where it reported that respiratory conditions were linked with higher ED utilization [10]. Focusing on ED revisits related to respiratory diseases may reduce ED revisit rates by identifying non-urgent ED visits.

In this large cohort study, we noted that the rate of ED revisits decreased with age in children with chronic diseases. The greater ED revisit rate in younger children noted in the study is in agreement with earlier studies showing that children of a younger age are associated with frequent ED revisits $[9,12,15,18]$. Interventions are needed to reduce ED revisits in younger children, such as referrals or early follow-up appointments in the outpatient clinic setting to specialty clinics, and parent involvement in the ED discharge process.

In this study, institutional health insurance coverage was found to be an important determinant of ED revisits in children with chronic diseases. In several reports, public health insurance coverage as compared with uninsured (self-pay) or privately insured has been cited as an important predictor of ED revisits. Walsh-Kelly et al. [18] noted that public insurance was associated with greater ED revisits. Scales et al. [19] and Jacobstein et al. [20] reported that the odds of ED revisits were 52 and 86\% higher in the Medicaid group as compared to the private insurance group, respectively. The impact of institutional health insurance coverage on ED revisits in children with chronic diseases must be evaluated to identify preventable reasons for ED revisits. 
A higher rate of ED revisits in children with chronic diseases appeared during the year 2015 as compared to the more recent year of 2017. This indicates that the rate of ED revisits in the Saudi facility decreased with time. This may be due to the 2015 implementation in the KASCH-RD facility of a new computerized hospital system, BESTCare, which is a unified electronic health information system that includes a clinical decision support system. The reduction of the ED revisit rate over time could be due to implementation of a wide array of training programs to promote and evaluate the use BESTCare among physicians.

Studies have shown that electronic health information systems, particularly those that incorporate clinical decision tools, have the advantage of improving the healthcare provider's adherence to evidence-based clinical guidelines and care protocols $[27,28]$. Improvements in adherence can lead to improved clinical outcomes [2731 ] and potentially better quality of patient care, which may help to explain the reduction in ER revisits. However, it should be noted that these studies have taken place at inpatient and outpatient settings and not the $E R$, and thus have not directly assessed the effect of clinical decision tools.

The authors identified several limitations to the study. Although the number of ED visits studied was high, the findings were based on a single-center and retrospective study rather than a multi-center and prospective assessment of within $72 \mathrm{~h}$ of ED revisits. We did not record ED revisits occurring at another health facility. Furthermore, the study has not collected data on important details such as mode of arrival to the ED, number of chronic diseases, physician-related causes, and patient-related causes. Despite these limitations, to our knowledge, this study represents an initial investigation on early ED revisits and their causes among Saudi Arabian children with chronic diseases.

\section{Conclusions}

A high rate of early ED revisits was found at KASCH-RD among children with chronic diseases, occurring frequently in one in ten children. In children with chronic diseases, higher ED revisit rates are associated with young age, institutional health insurance coverage, and causes for ED visits. Intervention could be implemented to examine whether parent education on home management, early follow-up appointment in an outpatient clinic setting, and clear discharge guidance could reduce the rate of early ED revisits among children with chronic diseases.

\section{Abbreviations}

aRR: Adjusted relative rate; Cl: Confidence interval; ED: Emergency Department; IRB: Institutional Review Board; KASCH-RD: King Abdullah Specialist Children's Hospital, Riyadh; MNG-HA: Ministry of National Guard Health Affairs; P: $p$-value; uRR: Unadjusted relative rate

\section{Acknowledgements}

The authors would like to thank the Ministry of National Guard - Health Affairs, Riyadh, Saudi Arabia, for approving this study.

\section{Availability of data and materials}

The electronic health records dataset analyzed in the current study are not publicly available due to concerns regarding security and privacy of the health records. The original health records dataset pertaining to this study can be obtained from the Ministry of National Guard - Health Affairs.

\section{Authors' contributions}

AEA and DKM developed the study, analyzed the data, and wrote the manuscript. DAA, HRA, MNA, and BIA retrieved the data from the BESTCare records and used the International Classification of Diseases (ICD-10) to determine the cause of ED visits. MAA1 retrieved and reviewed data quality and cross-checked analysis. MAA2, HJ, and MN commented on the methods and clinical findings. All authors read and approved the final manuscript.

\section{Ethics approval and consent to participate}

The study (approval \#RC17/081/R) was approved by the Institutional Review Board (IRB) at the Ministry of National Guard Health Affairs (MNGHA), Riyadh, Saudi Arabia. The patients' consent to review their medical records was not required by the ethical review committee. No identifier was used, and privacy and confidentiality of patients were completely protected.

\section{Consent for publication}

Not applicable.

\section{Competing interests}

The authors declare that they have no competing interests.

\section{Competing interests}

The authors declare that they have no competing interests.

\section{Publisher's Note}

Springer Nature remains neutral with regard to jurisdictional claims in published maps and institutional affiliations.

\section{Author details}

${ }^{1}$ King Abdullah International Medical Research Center (KAIMRC), Riyadh, Saudi Arabia. ${ }^{2}$ King Saud bin Abdulaziz University for Health Sciences, National Guard Health Affairs, P.O. Box 22490, Riyadh 11426, Saudi Arabia. ${ }^{3}$ Department of Biostatistics, School of Medicine, Virginia Commonwealth University, Box 980032, Richmond, VA 23298, USA. ${ }^{4}$ McGill University, Montreal, Canada. ${ }^{5}$ Pulmonary Division Medical Director of sleep disorders, Center King Abdulaziz Medical City, Riyadh, Saudi Arabia.

Received: 1 April 2018 Accepted: 21 June 2018

Published online: 26 June 2018

\section{References}

1. Monuteaux MC, Lee L, Fleegler E. Children injured by violence in the United States: emergency department utilization, 2000-2008. Acad Emerg Med. 2012;19(5):535-40.

2. Meier JD, Valentine K, Hagedorn C, Hartling C, Gershan W, Muntz HR, Murphy NA. Emergency department use among children with tracheostomies: avoidable visits. J Pediatr Rehabil Med. 2015;8(2):105-11.

3. Hasegawa K, Tsugawa Y, Cohen A, Camargo CA Jr. Infectious disease-related emergency department visits among children in the United States. Pediatr Infect Dis J. 2015;34(7):681.

4. Lawrence LM, Jenkins CA, Zhou C, Givens TG. The effect of diagnosisspecific computerized discharge instructions on 72-hour return visits to the pediatric emergency department. Pediatr Emerg Care. 2009;25(11):733-8.

5. Cheng SY, Wang HT, Lee CW, Tsai TC, Hung CW, Wu KH. The characteristics and prognostic predictors of unplanned hospital admission within 72 hours after ED discharge. Am J Emerg Med. 2013;31(10):1490-4.

6. Tsai IT, Sun CK, Chang CS, Lee KH, Liang CY, Hsu CW. Characteristics and outcomes of patients with emergency department revisits within 72 hours and subsequent admission to the intensive care unit. Tzu Chi Med J. 2016; 28(4):151-6. 
7. Machado V, Peças S, Periquito I, Mota A, Veiga E, de Jesus Balseiro M. Children who leave the emergency department: missing opportunities? Acta Medica Port. 2014;27(5):568-75.

8. Motosue MS, Bellolio MF, Van Houten HK, Shah ND, Campbell RL. Increasing emergency department visits for anaphylaxis, 2005-2014. J Allergy Clin Immunol Pract. 2017;5(1):171-5.

9. Cho CS, Shapiro DJ, Cabana MD, Maselli JH, Hersh AL. A national depiction of children with return visits to the emergency department within 72 hours, 2001-2007. Pediatr Emerg Care. 2012;28(7):606-10.

10. Goh GL, Huang P, Kong MC, Chew SP, Ganapathy S. Unplanned reattendances at the paediatric emergency department within 72 hours: a one-year experience in KKH. Singap Med J. 2016;57(6):307.

11. Goldman RD, Kapoor A, Mehta S. Children admitted to the hospital after returning to the emergency department within 72 hours. Pediatr Emerg Care. 2011;27(9):808-11.

12. Sung SF, Liu KE, Chen SC, Lo CL, Lin KC, Hu YH. Predicting factors and risk stratification for return visits to the emergency department within 72 hours in pediatric patients. Pediatr Emerg Care. 2015;31(12):819-24.

13. Freedman SB, Thull-Freedman JD, Rumantir M, Atenafu EG, Stephens D. Emergency department revisits in children with gastroenteritis. J Pediatr Gastroenterol Nutr. 2013;57(5):612-8.

14. Berry JG, Rodean J, Hall M, Alpern ER, Aronson PL, Freedman SB, Brousseau DC, Shah SS, Simon HK, Cohen E, Marin JR. Impact of chronic conditions on emergency department visits of children using Medicaid. J Pediatr. 2017; 182:267-74.

15. Angoulvant F, Jumel S, Prot-Labarthe $S$, Bellettre $X$, Kahil M, Smail A, Morin L, Alberti C. Multiple health care visits related to a pediatric emergency visit for young children with common illnesses. Eur J Pediatr. 2013;172(6):797-802.

16. Ryan J, Hendler J, Bennett KP. Understanding emergency department 72hour revisits among medicaid patients using electronic healthcare records. Big data. 2015;3(4):238-48.

17. Shy BD, Kim EY, Genes NG, Lowry T, Loo GT, Hwang U, Richardson LD, Shapiro JS. Increased identification of emergency department 72-hour returns using multihospital health information exchange. Acad Emerg Med. 2016;23(5):645-9.

18. Walsh-Kelly CM, Kelly KJ, Drendel AL, Grabowski L, Kuhn EM. Emergency department revisits for pediatric acute asthma exacerbations: association of factors identified in an emergency department asthma tracking system. Pediatr Emerg Care. 2008;24(8):505-10.

19. Scales CD, Lin L, Saigal CS, Bennett CJ, Ponce NA, Mangione CM, Litwin MS. Emergency department revisits for patients with kidney stones in California. Acad Emerg Med. 2015;22(4):468-74.

20. Jacobstein CR, Alessandrini EA, Lavelle JM, Shaw KN. Unscheduled revisits to a pediatric emergency department: risk factors for children with fever or infection-related complaints. Pediatr Emerg Care. 2005;21(12):816-21.

21. Al Qahtani M, Al Backer T, Al Anazi T, Al Johani N, Binsalih S, AlGobain M, Alshammari H. Impact of lipid disorders on mortality among Saudi patients with heart failure. J Saudi Heart Assoc. 2015;27(2):91-5.

22. Al-Otaibi NG, Zeinelabdin M, Shalaby MA, Khathlan N, Mashat GD, Zahrani AA, NoorSaeed SM, Shalabi NM, Alhasan KA, Sharief SN, Albanna AS. Impact of acute kidney injury on long-term mortality and progression to chronic kidney disease among critically ill children. Saudi Med Jl. 2017;38(2):138.

23. Yoo S, Lee KH, Lee HJ, Ha K, Lim C, Chin HJ, Yun J, Cho EY, Chung E, Baek RM, Chung CY. Seoul National University Bundang Hospital's electronic system for total care. Healthcare Inform Res. 2012;18(2):145-52.

24. WHO. Noncommunicable Diseases (2016). Available from: http://www.who. int/topics/noncommunicable_diseases/en/. Accessed 2 Mar 2018.

25. Al-Turki YA. Overview of chronic diseases in the Kingdom of Saudi Arabia. Saudi Med J. 2000:21(5):499-500.

26. World Health Organization. ICD-10 version: 2016. Geneva: World Health Organization; 2016. [cited 2017 May 12]

27. Menachemi N, Collum TH. Benefits and drawbacks of electronic health record systems. Risk Manag Healthcare Policy. 2011;4:47.

28. Forrest CB, Fiks AG, Bailey LC, Localio R, Grundmeier RW, Richards T, Karavite DJ, Elden L, Alessandrini EA. Improving adherence to otitis media guidelines with clinical decision support and physician feedback. Pediatrics. 2013; 131(4):e1071-81.

29. Niès J, Colombet I, Zapletal E, Gillaizeau F, Chevalier P, Durieux P. Effects of automated alerts on unnecessarily repeated serology tests in a cardiovascular surgery department: a time series analysis. BMC Health Serv Res. 2010;10(1):70.
30. Rossi RA, Every NR. A computerized intervention to decrease the use of calcium channel blockers in hypertension. J Gen Intern Med. 1997; 12(11):672-8.

31. Willson D, Ashton C, Wingate N, Goff C, Horn S, Davies M, Buxton R. Computerized support of pressure ulcer prevention and treatment protocols. In Proceedings of the annual symposium on computer application in Medical Care American Medical Informatics Association. 1995 (p. 646)

\section{Ready to submit your research? Choose BMC and benefit from:}

- fast, convenient online submission

- thorough peer review by experienced researchers in your field

- rapid publication on acceptance

- support for research data, including large and complex data types

- gold Open Access which fosters wider collaboration and increased citations

- maximum visibility for your research: over $100 \mathrm{M}$ website views per year

At BMC, research is always in progress.

Learn more biomedcentral.com/submissions 